\title{
Evaluation of knowledge base of hospital pharmacists and physicians on herbal medicines in Southwestern Nigeria
}

\author{
Titilayo O FAKEYE, Oluchi ONYEMADU. \\ Received (first version): 18-Sep-2007 Accepted: 14-Mar-2008
}

\begin{abstract}
${ }^{*}$
The use of herbal medicines among Nigerian patients and the tendency to combine this class of medicines with allopathic drugs while on hospital admission have been on the increase. Earlier studies show that community pharmacists from Nigeria believe that they need more training to counsel patients on their use of herbal medications. Objective: To evaluate knowledge base, use, acceptability, attitudes and beliefs of hospital pharmacists and physicians in South-western Nigeria on herbal products / phytopharmaceuticals /dietary supplements (HP/PP/DS).

Methods: A 20-odd questionnaire including an 8item herbal medicine question was used to assess the knowledge of the physicians and pharmacists in the area of pharmacology of HP/PP/DS. Effects of demographic information such as age, sex, year post graduation, years of experience and area of specialization on the scores obtained were evaluated using Fisher's exact tests. Level of significance was set at $p<0.05$.

Results: Pharmacists (51.4\%) believed that the training they had was not adequate while physicians (44.6\%) believed HP/PP/DS are not safe and 18.5\% believed they are not effective. Pharmacovigilance centres were not significantly used for adverse reactions reported by patients. Pharmacists $(67.6 \%)$ and physicians $(29.3 \%)$ believed phytopharmaceuticals interact with other drugs. Year of graduation had a significant effect on the perception of the possibilities of interaction for pharmacists. $5.6 \%$ of the physicians and $62.4 \%$ of the pharmacists scored $\geq 50 \%$ with the questions on use and interaction potentials of HP/PP/DS, with cadre and years of practice having significant effects.

Conclusions: There is a deficiency in the knowledge base of physicians, especially on the pharmacology and potential interaction of herbal medicines. There is an urgent need for the inclusion of pharmacology of common herbal medicines in the curriculum of Nigerian medical degree and an improvement in the pharmacy curriculum in this area.
\end{abstract}

Keywords: Medicine, Herbal. Herb-Drug Interactions. Pharmacists. Physicians. Nigeria.

\footnotetext{
"Titilayo O FAKEYE, Department of Clinical Pharmacy \& Pharmacy Administration, University of Ibadan (Nigeria). Oluchi ONYEMADU. Department of Clinical Pharmacy \& Pharmacy Administration, University of Ibadan, Ibadan (Nigeria)
}

\author{
EVALUACIÓN DEL CONOCIMIENTO DE \\ FARMACÉUTICOS Y MÉDICOS SOBRE \\ PLANTAS MEDICINALES EN EL \\ SUROESTE DE NIGERIA
}

\section{RESUMEN}

El uso de plantas medicinales entre los pacientes nigerianos y la tendencia a combinarlas con los medicamentos alopáticos mientras están hospitalizados han ido en aumento. Anteriores estudios muestran que los farmacéuticos comunitarios de Nigeria creen que necesitan más formación para aconsejar pacientes en el uso de sus plantas medicinales.

Objetivo: Evaluar el conocimiento, uso, aceptabilidad, actitudes y creencias de los farmacéuticos y médicos de hospital en el Suroeste de Nigeria ante las plantas

medicinales/fitoterapia/suplementos dietéticos (PM/FT/SD)

Métodos: Se usó un cuestionario de 20 preguntas que incluía 8 de plantas medicinales para evaluar conocimiento de los médicos y farmacéuticos sobre la farmacología de PM/FT/SD. Mediante la prueba exacta de Fischer, se evaluaron los efectos de los datos demográficos tal como edad, sexo, año de graduación, años de experiencia y área de especialización, sobre las puntuaciones obtenidas. El nivel de significación se situó en $\mathrm{p}<0.05$. Resultados: Los farmacéuticos $(51,4 \%)$ creían que la formación que tenía no era adecuada, mientras que los médicos $(44,6 \%)$ creían que los $\mathrm{PM} / \mathrm{FT} / \mathrm{SD}$ no son seguros y el $18,5 \%$ que no eran efectivos. Los centros de farmacovigilancia no se usaban significativamente para comunicar reacciones reportadas por los pacientes. Los farmacéuticos $(67,6 \%)$ y los médicos $(29,3 \%)$ creían que los fitoterápicos interaccionaban con otros medicamentos. El año de graduación tuvo un efecto significativo en la percepción de las posibilidades de interacción por los farmacéuticos. El 5,6\% de los médicos y el $62,4 \%$ de los farmacéuticos puntuaron $\geq 50 \%$ a las preguntas sobre uso y interacciones potenciales de $\mathrm{PM} / \mathrm{FT} / \mathrm{SD}$, teniendo los años de ejercicio un efecto significativo.

Conclusiones: Hay deficiencia en el conocimiento de los médicos, especialmente en la farmacología y las interacciones potenciales de las plantas medicinales. Hay una necesidad urgente de la inclusión de la farmacología de las plantas medicinales comunes en la licenciatura en medicina en Nigeria y la mejoría de esta área en el currículo de farmacia. 
Palabras clave: Plantas medicinales. Interacciones Plantas-medicamentos. Farmacéuticos. Médicos. Nigeria.

\section{INTRODUCTION}

There seems to be an unprecedented increase in the use of herbal products / phytopharmaceuticals / dietary supplement (HP/PP/DS) in industrialized countries with a more general acceptance than has been hitherto witnessed. Reports of patients combining allopathic medicines with HP/PP/DS usually without the doctors or other health care givers' knowledge or awareness have also been on the increase. ${ }^{1,2}$ Though there is a record of increase in acceptance level of complementary and alternative medicine (CAM) by pharmacists ${ }^{3,4}$, physicians $^{5-7}$ and other health care givers ${ }^{8}$, the incidence of combining CAM with allopathic medicines without the awareness of the health professionals $^{1,2,9}$ may endanger therapy as a result of unexpected interactions and adverse drug reaction which may be traced to the use of the combinations.

Previous studies in industrialized countries ${ }^{1,10,11}$ and developing countries ${ }^{5,6,12}$ show a relatively poor knowledge of HP/PP/DS vis a vis interaction potential and toxic effects among health care givers. However, pharmacists generally seem to be more knowledgeable than physicians, who are in turn better informed than nurses and trainees. ${ }^{11}$ There also seems to be better correlation with health care givers who use HP/PP/DS having better knowledge than those who do not. ${ }^{11}$

Literatures abound on the knowledge base of physicians and sometimes pharmacists with respect to HP/PP/DS in Europe, USA and some other developing nations such as Turkey and Malaysia. In Nigeria, however, extensive literature search shows that very little has been done on assessing the knowledge base of pharmacists on HP/PP/DS ${ }^{12}$ and that apparently nothing has been done on assessing physicians. This study has therefore been designed to evaluate two groups of professionals that patients usually come across in the hospital - the pharmacist and the physician. The use, acceptability, attitudes to and beliefs in $\mathrm{HP} / \mathrm{PP} / \mathrm{DS}$ and their knowledge base on interactions of some of the common HP/PP/DS, usually stocked in the pharmacies of secondary and tertiary hospitals in Nigeria, were evaluated in this study.

\section{METHODS}

A pilot study was carried out to itemize the herbal medicines used or stocked in government-owned secondary and tertiary care hospitals in the Southwestern part of Nigeria. Herbal medicines in this study are defined as refined or raw extracts of plant origin, excluding minerals and vitamins, formulated into pharmaceutical formulations such as tablet, capsule, syrup and other oral dosage forms.
Multivitamin formulations containing ginseng, Gingko biloba or dietary supplements, such as those used for sickle cell disease, were also regarded as herbal medicine. The study was conducted in compliance with the ethical requirements of studies involving human beings. Informed consent of the individuals was obtained before the questionnaires were administered and anonymity of the respondents was upheld.

Two states in the southwestern part of Nigeria were chosen for the study. In the locality, there are two teaching hospitals and over 30 secondary or general hospitals. In the capital cities of both states, all the secondary hospitals were chosen for the study.

Inclusion criteria were physicians and pharmacists in government hospital practice. The number of pharmacists was obtained from the administration office of each hospital. The number of physicians was obtained from the Department of Medicine in the teaching hospitals. Secondary hospitals had to be included due to the low number of pharmacists in the tertiary hospitals. Private hospitals were excluded from the studies because most of them use pharmacy technicians or nurses for drug dispensing. In all, there were 101 hospital pharmacists and 350 physicians. One hundred and fifty physicians gave their consent to take part in the study.

Twenty two and 24 item questionnaires were used to evaluate the use, attitude, belief and knowledge base of physicians and pharmacists respectively on herbal medicines and phytopharmaceuticals (HP/PP/DS) in the chosen study centres. The questionnaires were pre-tested among five hospital pharmacists and four physicians before distribution to the respondents.

In the case of physicians, demographic information such as age, sex, cadre in practice, number of years of post graduation, and, in the case of pharmacists, demographic data, years of experience (which may be different from years post of graduation), and area of specialization (for the physicians) were obtained. Multichoice questions regarding use, safety, knowledge and training of the physicians and pharmacists in the area of phytopharmaceuticals were also included. Eight questions were used to assess the knowledge of the physicians and pharmacists in the areas of indication and interaction potentials of the common phytopharmaceuticals available in most of the hospitals. Each question contained one right answer and three wrong answers. Correct answers to the questions were obtained from peer-reviewed journal articles on the subject. ${ }^{13-18}$ The right answer to the question carried a score of " 1 ", while a wrong answer carried a score of "0".

The limitation experienced in this study was the inaccessibility of the physician consultants and chief pharmacists. The excuses usually given were lack of time, for both parties and lack of interest in HP/PP/DS by the consultant physicians.

Descriptive statistics were used to evaluate the responses obtained. Comparison of the scores by 
the pharmacists and physicians, and the influence of certain variables on knowledge base were evaluated using Fisher's Exact test. Significant difference was set at $p \leq 0.05$.

\section{RESULTS}

The response rate was $92 \%$ for physicians and $74 \%$ for hospital pharmacists. The distribution according to sex showed that there were more males than females for physicians $(73.9 \%$ male; $26.1 \%$ females), while for pharmacists, the distribution was almost equal (43.2\% male; $56.7 \%$ female). There were $64.8 \%$ grade 1 pharmacists, $22.9 \%$ senior pharmacists, $10.8 \%$ principal pharmacists and $1.4 \%$ chief pharmacists. The pharmacists who graduated in $1990-1995$ were $8.1 \% ; 29.7 \%$ in $1996-2000$ and $62.2 \%$ in $2001-2006$. Majority $(72.9 \%)$ had been practising for $1-5$ years, $25.1 \%, 6-10$ years and $1.35 \%, 11-15$ years. There were $61.95 \%$ house officers, $30.4 \%$ registrars, $6.5 \%$ senior registrars and $1.1 \%$ consultants. Majority of the physicians $(85.9 \%)$ had been practising for $1-5$ years, $13.0 \%$ for $6-10$ years, and $1.1 \%$ for $11-15$ years.

Almost half of the pharmacists $(46.5 \%)$ found the training they had adequate while a higher number $(51.4 \%)$ believed that the training was not adequate, and that there is a need to have more intensive training in the field of herbal medicine than the one they had in the university. Only $1.1 \%$ were not sure whether or not pharmacists had adequate capability in the field of phytomedicine/phytotherapy. A large number of pharmacists $(67.6 \%)$ claimed that patients request for phytopharmaceuticals while only $15.2 \%$ physicians claimed that they had requests for phytopharmaceuticals from patients. A low number of pharmacists $(13.5 \%)$ had requests for phytopharmaceuticals on a weekly basis while $47.3 \%$ had them on a monthly basis. Most pharmacists $(80 \%)$ believed phytopharmaceuticals are safe and could be effective if properly administered. The remaining $20 \%$ were not too sure of the efficacy and safety. A large number of physicians, $44.6 \%$, believed they were not safe and $18.5 \%$ believed they were not effective. $3.3 \%$ and $7.6 \%$ believed they were safe and effective respectively while $1.1 \%$ believed they only had placebo-effect; $26.1 \%$ had no idea about the safety and efficacy of this group of pharmaceuticals.

When asked on the steps taken after reports of possible interactions or adverse drug reactions (ADR) were made, $31.1 \%$ of pharmacists (majority of whom graduated between 1996 and 2000) and $13 \%$ of physicians (majority of whom graduated between 2001 and 2006) claimed they reported to the institutional pharmacovigilance centers. Others simply informed the patients to stop using the offending agent. Some examples of the interaction or adverse reactions given by the patients included nausea $(34.5 \%)$, itching of the skin $(23.2 \%)$ and headache $(50 \%)$ which stopped when the HP/PP/DS was withdrawn. A large number of pharmacists $(67.6 \%)$ believed interactions are possible with phytopharmaceuticals while $17.6 \%$ believed interactions are not possible. The remaining $14.8 \%$ were not sure. On the other hand,
$29.3 \%$ physicians believed it was possible for phytopharmaceuticals to interact with other drugs while $10.9 \%$ believed it was not possible. Others $(59.8 \%)$ were not sure. In-between professions, cadre and year of graduation had a significant effect $(p<<0.05)$ on the perception of the possibilities of phytopharmaceuticals interacting with other drugs. For pharmacists, more respondents with 5 years or less of post graduation experience (33.4\%) believed in possibility of interactions than physicians with the same years of post graduation experience (26\%). The same effect was also observed with respondents with $7-11$ years of graduation experience $(23.8 \%$ pharmacists and $2.2 \%$ physicians). A lower number of pharmacists (14.9\%) than physicians $(59.8 \%)$ claimed not to be aware that HP/PP/DS could interact with allopathic agents while a higher number of pharmacists $(67.6 \%)$ and 29.3\% physicians believed that HP/PP/DS could interact. Examples of the interactions given by the pharmacists include anticoagulant effect of warfarin which is potentiated by co administration of extracts of Gingko biloba or garlic.

Physicians (34.8\%) believed that only doctors should recommend HP/PP/DS to patients and $45.7 \%$ physicians believed it should be pharmacists. Almost twenty percent were of the opinion that the recommendation should be left to traditional medical practitioners (TMPs). Pharmacists $(78.4 \%)$, on the other hand believed that the recommendation should be done by pharmacists due to their training in HP/PP/DS, while $18.8 \%$ believed it should be by both doctors and pharmacists; $2.4 \%$ believed it should be handled by TMPs. Neither believed that patent medicine dealers should be allowed to recommend HP/PP/DS. All the pharmacists believed that the National Agency for Food \& Drug Administration and Control (NAFDAC) should be allowed to regulate the manufacture, sales and supply of HP/PP/DS as it is being presently done. One of the pharmacists also suggested that the Traditional Medical Board (TMB) should be involved. A large number of the physicians, $83.7 \%$, believed that NAFDAC should be in control but $19.5 \%$ believed that it should be done by NAFDAC in conjunction with the Medical Council of Nigeria and $32.6 \%$, NAFDAC and the Pharmacists Council of Nigeria. Others $(3.3 \%)$ believed it should be handled by the TMB. Table 1 shows the scores obtained by the physicians and pharmacists based on their cadre and years of practice.

\section{DISCUSSION}

In both groups of professionals, there was obvious reluctance on the part of the senior professionals to take part in the study. Reasons given when interviewed were lack of time (by the chief pharmacists) and lack of interest in HP/PP/DS (by the consultant physicians). This may have a negative impact on their junior colleagues.

On the issue of training, the pharmacists had more training at both formal and informal levels than the physicians. This is probably due to the pharmacy curriculum which includes topics in herbal medicines and related areas in the course of the 
Bachelor of Pharmacy degree training. The continuing education programme for recertification of pharmacists has also exposed some of the older pharmacists to some of the recent findings in HP/PP/DS. Scores obtained by pharmacists in the use and interaction of HP/PP/DS with allopathic agents confirmed that they had better training in HP/PP/DS. This training, which is part of the bachelor of pharmacy degree programme, was however rated as being inadequate by majority of the pharmacists. This seems the worldwide trend as pharmacists would want to know as much about HP/PP/DS as they do about allopathic agents. The physicians also underwent a mixture of formal and informal training but did not pass any comment on the adequacy of their training. The pharmacists believed they would gain a lot from a formal training, and advocated that the curriculum for the Bachelor of Pharmacy degree and continuing education have more elements of topics in pharmacology of herbal medicines, resembling their counterparts' in community practice in Nigeria ${ }^{12}$, Singapore ${ }^{3}$ and the United States. ${ }^{19}$ Previous studies ${ }^{10,11}$ showed that in Western countries, physicians are not adequately knowledgeable about HP/PP/DS. The contrast is the case in Trinidad $^{6}$ and Malaysia ${ }^{5}$ which are not western in orientation. Here, the physicians accept the use of HP/PP/DS and even recommend it to their patients. Since use has also been associated with better knowledge ${ }^{11}$, the result from the present study may be due to non acceptance of HP/PP/DS by majority of the physicians. Their opinion about the safety of HP/PP/DS showed that only $9.9 \%$ believed they were safe and or effective. There is also a wide discrepancy in the number of patients who approach each group of professionals for HP/PP/DS. This may be due to the patients' perception that the physicians are not so receptive to the use of HP/PP/DS. The discrepancy between the number of pharmacists who claimed to have received prescriptions for phytopharmaceuticals and the physicians who wrote the prescriptions shows that there is a serious difference probably in what is regarded as a HP/PP/DS by both professionals, even with HP/PP/DS defined on the questionnaires. The low number of physicians who prescribe phytopharmaceuticals is also most probably due to the perception of physicians regarding the efficacy and safety of herbs. Pharmacists tend to have a more regular request for HP/PP/DS. This is confirmed by the number of seeming interactions or adverse drug reactions (ADR) due to the use of HP/PP/DS that were reported by the pharmacists. There were twice more pharmacists than physicians who had received reports of interaction and ADRs. The step taken by both professionals thereafter was inadequate. The patients were asked to stop taking the offending agents and the number of reports made to the several pharmacovigilance centers in their area is insignificant compared to the complaints obtained. Again, the low number of reports made could be due to the level of unbelief that this class of medicines may not interact. This response could be confirmed from their responses to the potentials of HP/PP/DS interacting with allopathic agents $(67.6 \%$ pharmacists against $29.3 \%$ physicians). Virtually all the pharmacists believed that NAFDAC should be allowed to monitor and regulate sales and supply of HP/PP/DS, an opinion shared by the physicians even though they believed other agencies such as the Medical Council of Nigeria and the Pharmacists Council of Nigeria should be involved alongside NAFDAC. All the pharmacists also believed that due to their exposure to training in herbal medicines, they are best fit to recommend HP/PP/DS to patients, but a large number of physicians did not share this opinion.

\begin{tabular}{|c|c|c|c|c|c|}
\hline \multirow[t]{3}{*}{ Variable } & \multicolumn{4}{|c|}{ Number of respondents obtaining scores } & \multirow[t]{4}{*}{$P$ value } \\
\hline & & & & & \\
\hline & \multirow[t]{2}{*}{ Pharmacists } & \multirow[t]{2}{*}{ Physicians } & \multirow[t]{2}{*}{ Pharmacists } & \multirow[t]{2}{*}{ Physicians } & \\
\hline Cadre & & & & & \\
\hline GP 1/Registrar & 17 & 26 & 31 & 2 & $0.0001^{* * *}$ \\
\hline PP/SR & 2 & 5 & 6 & 1 & $0.1026^{\mathrm{NS}}$ \\
\hline \multicolumn{6}{|l|}{ Years of Practice } \\
\hline $1-5$ & 18 & 78 & 36 & 1 & $<0.0001^{* * *}$ \\
\hline $6-10$ & 6 & 9 & 13 & 3 & $0.0290^{\star *}$ \\
\hline General & 24 & 87 & 50 & 5 & $<0.0001^{\star * *}$ \\
\hline
\end{tabular}

Years of experience had a positive effect on the ability of the pharmacists to score above $50 \%$ in the test. For the physicians, however, years of graduation/years of experience had no effect on the score. Neither those with many years of experience nor those with less than 5 years experience had a good score, confirming a study in the US by Suchard et $\mathrm{al}^{10}$ in which clinical experience, among other factors, did not correlate significantly with the physicians' knowledge of adverse effects of herbal medicines. Years of practice as hospital pharmacists generally favored pharmacists' knowledge base. New pharmacy graduates had higher scores than those who had graduated over 6 years before the study. Generally, the pharmacists had higher scores than the physicians.

\section{CONCLUSIONS}

There is a wide gap in the knowledge of physicians when compared to that of hospital pharmacists in the pharmacology of herbal medicines and phytopharmaceuticals. There is a need to include some of the important topics on the pharmacology 
of common herbs in the locality in the curriculum and in the existing continuing education programmes, workshops, seminars and knowledge update organized for these two health care professionals. This will help them to recognize some of the ADRs that may come up as a result of ingestion of HP/PP/DS, the inherent dangers involved in combining them with allopathic agents and counsel patients' knowledgeably on their use of phytopharmaceuticals. Also, pharmacovigilance centers where information can be disseminated to other health care professionals on some of the cases of herb-drug interactions and herb ADRs observed in hospitals are not adequately used. There is a need to intensify and educate health care professionals on the importance and usefulness of pharmacovigilance centers to patient care.

\section{CONFLICT OF INTEREST}

None declared.

\section{References}

1. Molassiotis A, Fernadez-Ortega P, Pud D, Ozden G, Scott JA, Panteli V, Margulies A, Browall M, Magri M, Selvekerova S, Madsen E, Milovics L, Bruyns I, Gudmundsdottir G, Hummerston S, Ahmad AM, Platin N, Kearney N, Patiraki E. Use of complementary and alternative medicine in cancer patients: a European survey. Ann Oncol. 2005;16(4):655-663. doi 10.1093/annonc/mdil 10

2. Howell L, Kochhar K, Saywell R Jr, Zollinger T, Koehler J, Mandzuk C, Sutton B, Sevilla-Martir J, Allen D. Use of herbal remedies by Hispanic patients: do they inform their physician? J Am Board Fam Med. 2006;19(6):566-578.

3. Koh HL, Teo HH, Ng HL. Pharmacists' pattern of use, knowledge and attitudes toward complementary and alternative medicine. J Altern Complement Med. 2003;9(1):51-63 . doi 10.1089/107628003321536940

4. Jörgensen TM, Andersson KA, Mårdby AC.. Beliefs about medicines among Swedish pharmacy employees. Pharm World Sci. 2006;28(4):233-238. doi 10.1007/s11096-005-2907-2

5. Aziz Z. Herbal medicines: predictors of recommendation by physicians. J Clin Pharm Ther 2004;29(3):241-246. doi 10.1111/j.1365-2710.2004.00562x

6. Clement YN, Williams AF, Khan K, Bernard T, Bhola S, Fortuné M, Medupe O, Nagee K, Seaforth CE. A gap between acceptance and knowledge of herbal remedies by physicians: the need for educational intervention. BMC Complement Altern Med. 2005 Nov 18;5:20 doi 10.1186/1472-6882-5-20

7. Karadeniz C, Pinarli FG, Oğuz A, Gürsel T, Canter B.. Complementary alternative medicine use in a paediatric oncology unit in Turkey. Pediatr Blood Cancer 2007;48(5):540-543. doi 10.1002/pbc.21012

8. Gardiner $\mathrm{P}$, Woods $\mathrm{C}$, Kemper KJ.. Dietary supplement use among health care professionals enrolled in an online urriculum on herbs and dietary supplements BMC Complement Altern Med. 2006;126:21. doi 10.1186/1472-6882-6-21

9. Fakeye TO, Abu T, Adebisi O. A survey of of the use of herbs among patients attending secondary health care facilities in Southwestern Nigeria. J Herb Pharmacother (In press)

10. Suchard JR, Suchard MA, Steinfeldt JL.. Physician knowledge of herbal toxicities and adverse herb-drug interactions. Eur J Emerg Med. 2004;11(4):193-197.

11. Kemper KJ, Gardiner P, Gobble J, Woods C.. Expertise about herbs and dietary supplements among diverse health professionals BMC Complement Altern Med. 2006;6:15. doi 10.1186/1472-6882-6-15

12. Adisa R, Fakeye TO. Assessment of the knowledge of community pharmacists regarding common phytopharmaceuticals sold in south western Nigeria. Trop J Pharm Res. 2006; 5(2):619-625.

13. Janetzky K, Morreale AP.. Probable interaction between warfarin and ginseng. Am J Health Sys Pharm. 1997;54:692693.

14. Matthews MK Jr.. Association of Ginkgo biloba with intracerebral hemorrhage. Neurology 1998; 50:1933-1934.

15. Johne A, Brockmöller J, Bauer S, Maurer A, Langheinrich M, Roots I.. Pharmacokinetic interaction of digoxin with an herbal extract from St. John wort (Hypericum perforatum). Clin Pharmacol Ther 1999;66:338-345. doi 10.1053/cp.1999.v66.a101944

16. Ko R. Adverse reactions to watch for in patients using herbal remedies. Western Journal of Medicine 1999;171(3):181186.

17. Fugh-Berman A, Ernst E. Herb-drug interaction: review and assessment of report reliability. $\mathrm{Br} \mathrm{J}$ Clin Pharmacol. 2001;52:587-595. doi 10.1046/j.0306-5251/2001.01469.x

18. Izzo AA, Ernst E. Interactions between herbal medicines and prescribed drugs: a systematic review. Drugs 2001;61:.2163-2175.

19. Chang ZG, Kennedy DT, Holdford DA, Small RE. Pharmacists' knowledge and attitude towards herbal medicine. Ann. Pharmacother. 2000;34(6):710-715. doi10.1345/aph.19263 